\title{
Geographic Access to Working Family Planning Centers and Unintended Pregnancies among Married Women: A Community Based Nested Case Control Study
}

\author{
Sumera Aziz Ali ${ }^{*}$, Sarah Saleem¹, Neelofar Sami'2, Mir Shabbar ${ }^{3}$, Muhammad Ahmed 3 , \\ Shafquat Rozi ${ }^{1}$, Robert L. Goldenberg ${ }^{4}$, Margo S. Harrison ${ }^{4}$, Omrana Pasha ${ }^{1}$ \\ ${ }^{1}$ Department of Community Health Sciences, Aga Khan University, Karachi, Pakistan \\ ${ }^{2}$ Willows Foundation, Karachi, Pakistan \\ ${ }^{3}$ Department of Urban and Infrastructure Engineering, NED University, Karachi, Pakistan \\ ${ }^{4}$ Department of OB/GYN, Columbia University Medical Center, New York, USA \\ Email: "sumera.ali@aku.edu, sarah.saleem@aku.edu,zoofi_14@yahoo.com,mshabbar@neduet.edu.pk, \\ muhammadahmed@neduet.edu.pk,Shafquat.Rozi@aku.edu,rlg88@columbia.edu, \\ margo.harrison@gmail.com, omrana.pasha@aku.edu
}

Received 4 January 2016; accepted 26 February 2016; published 29 February 2016

Copyright (C) 2016 by authors and Scientific Research Publishing Inc.

This work is licensed under the Creative Commons Attribution International License (CC BY).

http://creativecommons.org/licenses/by/4.0/

(c) (i) Open Access

\section{Abstract}

Background: Unintended pregnancies pose substantial risk to mothers and children. In Pakistan, unintended pregnancies account for $46 \%$ of all pregnancies. Lack of geographic access to open and well-supplied family planning (FP) centers may be related to the occurrence of such pregnancies, particularly in rural areas. Objective: The objective of this analysis is to determine if geographic access to family planning centers in the Thatta district of Pakistan is related to unintended pregnancy rates among married women. Methods: We conducted a community-based, nested casecontrol study of $\mathbf{8 0 0}$ pregnant women identified from the database of an active surveillance system, which registers and follows all pregnant women in the catchment area of Thatta district. Women were enrolled during the first trimester; those that reported their pregnancy to be unintended were selected as cases $(n=200)$, and those whose pregnancies were intended served as controls $(n=600)$. We defined geographic access as including both the distance of a family planning center from the woman's home, and availability of personal transportation. Logistic regression was used for analysis. Results: In the multivariate model, neither distance [OR $=1.0 ; 95 \% \mathrm{CI}$ $(0.95$ - 1.05)] nor availability of transportation $[O R=1.14 ; 95 \% \mathrm{CI}(0.78-1.67)]$ were significantly

\footnotetext{
${ }^{*}$ Corresponding author.
}

How to cite this paper: Ali, S.A., et al. (2016) Geographic Access to Working Family Planning Centers and Unintended Pregnancies among Married Women: A Community Based Nested Case Control Study. Open Journal of Epidemiology, 6, 95-108. http://dx.doi.org/10.4236/ojepi.2016.61010 
associated with unintended pregnancy. In fact, women with unintended pregnancies were more likely to be aware of family planning [OR $=2.21 ; 95 \% \mathrm{CI}(1.23-3.97)]$ and more likely to have been using a contraceptive method before conceiving their index pregnancy [OR $=3.59$; $95 \%$ CI $(1.83$ 7.06)]. Other factors related to unintended pregnancy were older maternal age $[\mathrm{OR}=1.13 ; 95 \% \mathrm{CI}$ $(1.08$ - 1.17)], having already had at least one son [OR = 3.13; 95\% CI (1.93 - 5.07)]; spousal opposition to contraceptive use, [OR $=3.24 ; 95 \% \mathrm{CI}(1.89-5.56)]$ and low spousal education level [OR = $1.85 ; 95 \%$ CI (1.08 - 3.18)] as compared to women with intended pregnancy. Conclusion: Lack of geographic access to FP centers is not a risk factor for unintended pregnancy in women from the Thatta district. However, in this population, unintended pregnancies are more common among older women, women having at least one son, and those who have a spouse who does not approve of contraceptive use, and is less educated. Of note, women who reported unintended pregnancy did have knowledge about FP and were more often using contraceptives before they conceived.

\section{Keywords}

\section{Unintended Pregnancy, Geographic Access, Family Planning}

\section{Introduction}

Unintended pregnancies have substantial, social, economic and health consequences on families [1]. Women with unintended pregnancies undergo unsafe abortions, do not seek antenatal care, and have worse pregnancy outcomes [2]. It was estimated that globally out of 210 million pregnancies in 2005, 75 to 80 million pregnancies were unintended and 42 to 46 million pregnancies were terminated [3].

In Pakistan, out of about 9 million pregnancies, $46 \%$ are believed to be unintended and $54 \%$ of these end in induced abortions [4]. Study from Karachi found that, around $88 \%$ of pregnancies ending in induced abortion occurred as a result of unintended pregnancies [5]. Furthermore, in Pakistan, current contraceptive prevalence rate (CPR) is $35 \%$, while total fertility rate (TFR) is 3.8 [6]. If unintended pregnancies are prevented, TFR in Pakistan would be reduced to 3.1 births per woman [6].

Women who experience unintended pregnancies either have an unmet need for contraception or experience a failure of the contraceptive method [7]. In Pakistan, 55\% of married women do not want to become pregnant, but only $26 \%$ use a modern contraceptive method, leaving $29 \%$ with an unmet need [6]. Women with unmet need either perceive that their pregnancy risk is low, experience opposition to contraceptive use, have little autonomy, do not have a son, fear side effects, or lack access to FP services [8].

Lack of access to FP services is considered an important risk factor of unmet need and/or unintended pregnancies [9]. Access has been defined as the "extent to which an appropriate package of contraceptive methods can be obtained in a given location" [10]. Lack of geographic access leads to a "decay effect" on utilization of health care services, which means that the further away a health center is from a community, the less likely patients are to utilize its services [11]. This effect is further aggravated by dearth of transportation, especially in rural areas [12]. Study from low and middle-income countries showed that distance from home to FP services is inversely proportional to CPR [13]. Another study from Bangladesh found that women living 5 miles or more away from a clinic facility were less likely to use contraceptives than those living 3 - 4 miles away [14]. In Pakistan only $10 \%$ of women live within walking distance of FP centers [15]. Although a network of public and private providers of FP services exists in Pakistan, but the rate of unintended pregnancies remains high. Limited geographic access to FP services is often cited as a contributor to low CPR among women of reproductive age. Thus, we wanted to evaluate the relationship of geographic access to unintended pregnancy in women from the rural Thatta district of Pakistan.

\section{Methodology}

\subsection{Study Design, Setting and Participants}

Since 2008, The Department of Community Health Sciences (CHS) at Aga Khan University (AKU) has maintained a maternal-newborn health (MNH) registry in 14 union councils (UC) of District Thatta [16] in Sindh province under the Global Network (GN) for Women's and Children’s Health Research [16]. We conducted a 
community-based, nested case-control study within this MNH registry from June 2011 to June 2012.

Pregnant women who were residents of the 14 UCs and were enrolled in MNH registry before 12 weeks of gestation were included in this study. Cases were defined as pregnant women who already had children and did not want more at all, or they wanted to have children but later on in their lives. The controls were pregnant women who reported their current pregnancy as intended. Pregnancy intention was assessed during the enrollment of participants in MNH registry. Geographic access to working FP centers was defined as distance in kilometers from women's homes to the FP centers and availability of transportation.

200 women who reported unintended pregnancy and 600 women who reported their pregnancy as intended. This sample size was based on proportion of exposure and other known risk factors of unintended pregnancy among controls ranging from $10 \%-70 \%$ [17], with a power of $80 \%$, significance level of $5 \%$,an odds ratio of at least 2, and keeping the ratio of 1:3 between cases and controls. This sample size was calculated by Open-Epi software.

Computer generated identification numbers of cases and controls were obtained from data management system of MNH registry and initially 2887 cases and 7368 controls were identified irrespective of any trimester at the time of enrollment. Based on the eligibility criteria of $\leq 12$ weeks of gestation during the index pregnancy, only 300 cases and 735 controls were identified from the MNH registry. Considering the required sample size, only 235 cases and 692 controls were approached for the interview and 35 cases and 92 controls were excluded due to different reasons as shown in Figure 1. Thus 200 cases and 600 controls met the inclusion criteria and also agreed to participate in the study.

The trained interviewers approached eligible participants by identifying their home addresses from the registry. A separate written informed consent was taken from each participant prior to inclusion in the study. Data about socio-demographic, socioeconomic, fertility-related, contraceptive use, and access-related factors were collected from women by data collectors. Information regarding knowledge about contraceptive methods and FP centers,

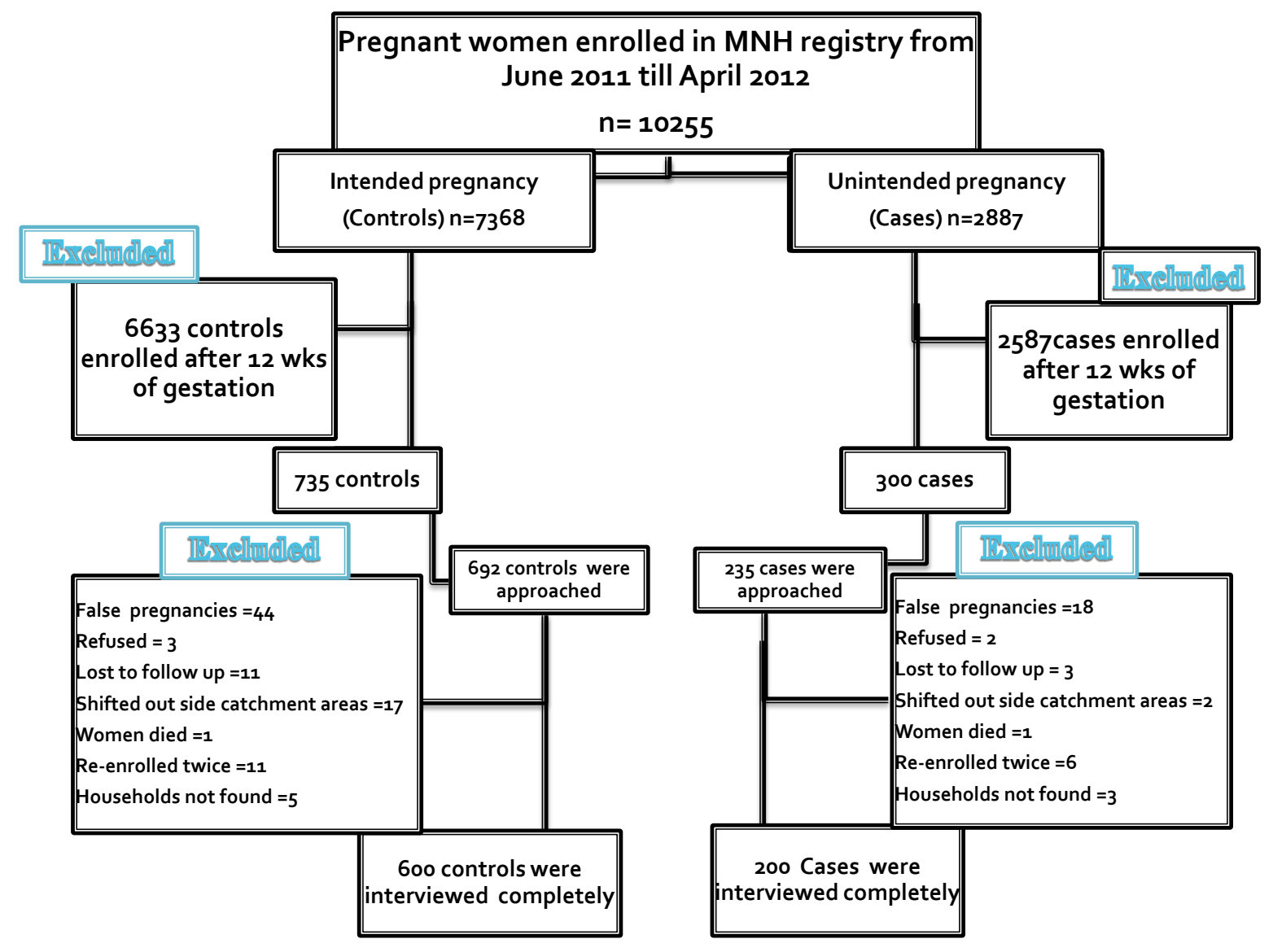

Figure 1. Flow of study participants during data collection period. 
home visits and FP services provision by lady health workers (LHW), were also collected from participants. LHW are female community health workers who provide a range of services including antenatal, postnatal, FP, and child health services by making home visits in the community [18]. All questions were asked in the local language with attention to maintaining privacy and confidentiality of participants. Moreover, coordinates (X (longitude, E)), (Y (latitude, N)) of homes and FP centers were also marked by data collectors using a Global Positioning System (GPS) unit.

\subsection{Measurement of Road Network Distance with the Help of Geographic Information System}

The data for geographic access, or the measurement of the distance from patient's homes to FP centers, was extracted from three sources: information on household address from the MNH registry, GPS data of sampled households and their nearest FP centers in the $14 \mathrm{UC}$, and through the determination of adigitized road network of the $14 \mathrm{UC}$ of Thatta district by the data collectors.

High resolution 0.6 m quick-bird satellite imagery was acquired from Google Earth Pro to develop geographic information system (GIS) database of transportation system of 14 UCs of the Thatta district. Satellite imagery plays a vital role in raster data handling, a type of geographic information system (GIS) data, by providing an excellent basis from which to then extract relevant geographic data information. The images of 14 UCs were downloaded in multiple steps requiring that individual images be mosaicked to obtain a single composite image of each UC that could be used for geo-rectification, or confirmation of geographic location, in order that individual FP centers would be able to be referenced by their exact pixel address [19].

Thatta district's road network includes national highway, paved, and non-paved roads (Figure 2). The GISbased digitized road map of 14 UC was developed, using ArcGIS software. Then, a GPS-based survey was conducted in the 14 UC to determine the exact location of FP centers. The coordinates of 84 centers, which included private clinics, LHW houses, government facilities, non-governmental organization (NGO) centers, and family welfare centers were marked using a GPS unit and these locations were incorporated with GIS as shown in Figure 3. Due to its large size and the complexity of the transportation system, Thatta district was divided into rural and urban regions. In urban regions, GPS coordinates were obtained in front of households of interest, while in rural areas, the center of the village was taken to get the coordinates, as shown in Figure 4.

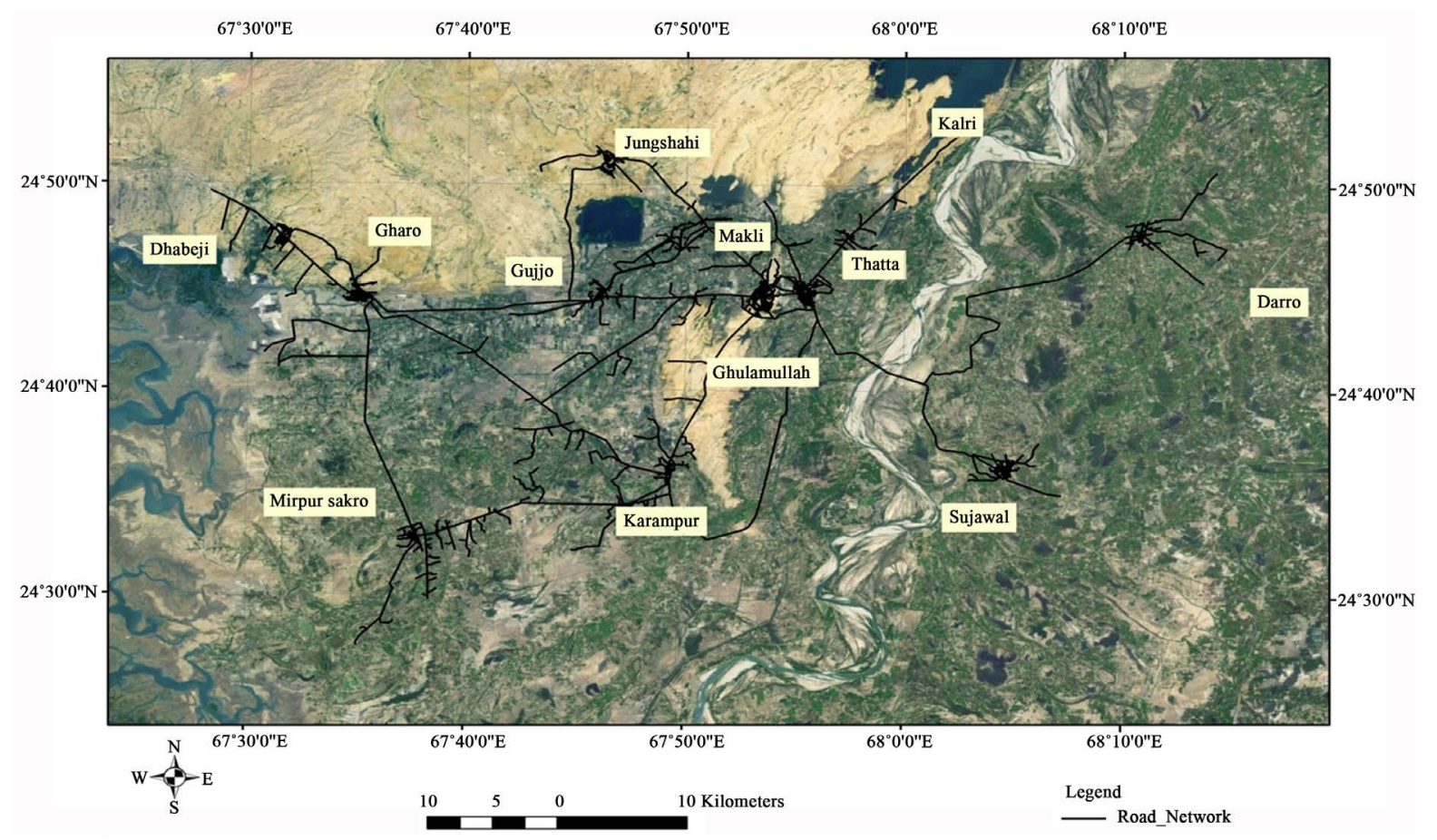

Figure 2. Road network including metal and non-metal roads in 14 union councils of District Thatta Sindh. 


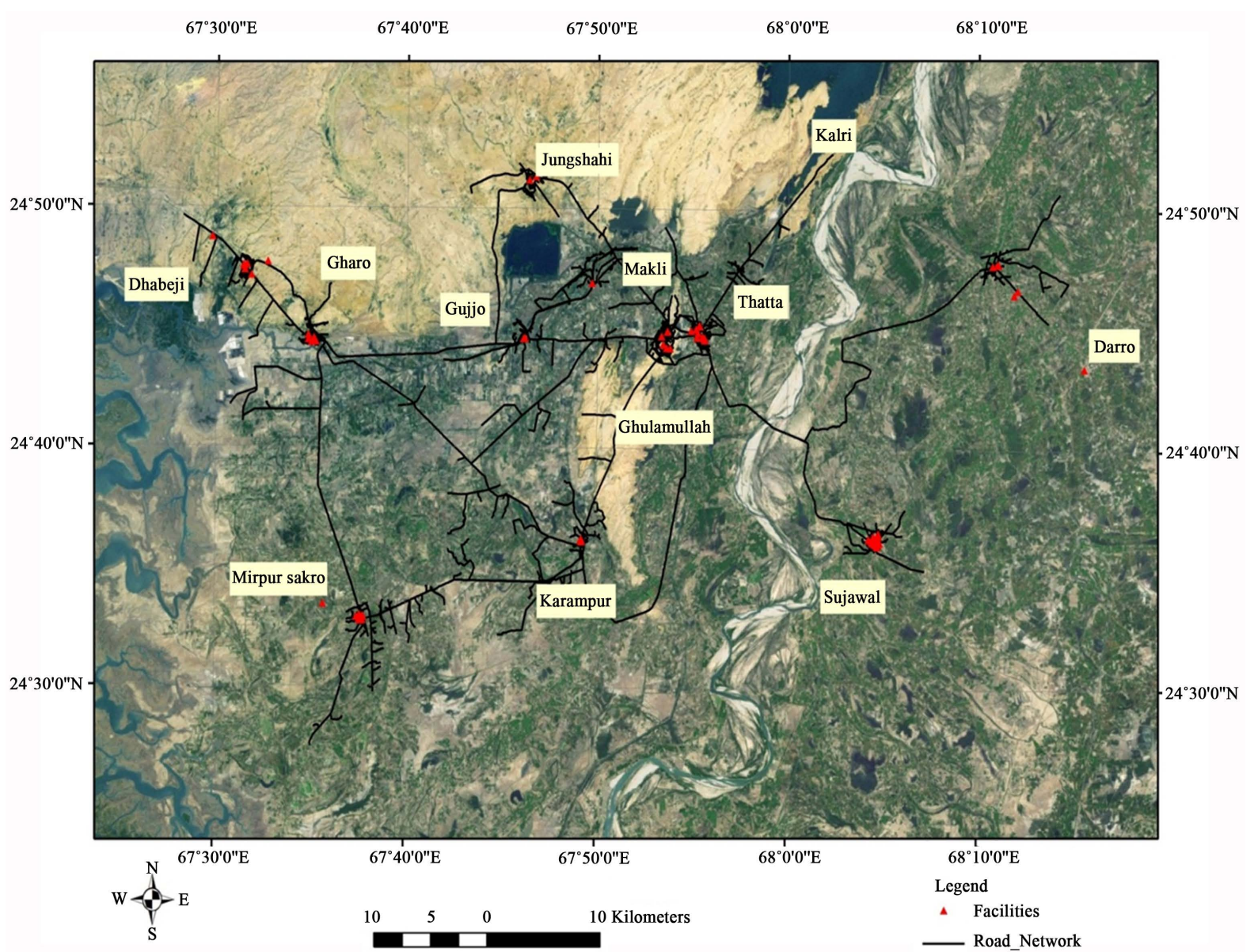

Figure 3. Spatial distribution of working family planning centers in 14 union councils of Thatta Sindh.

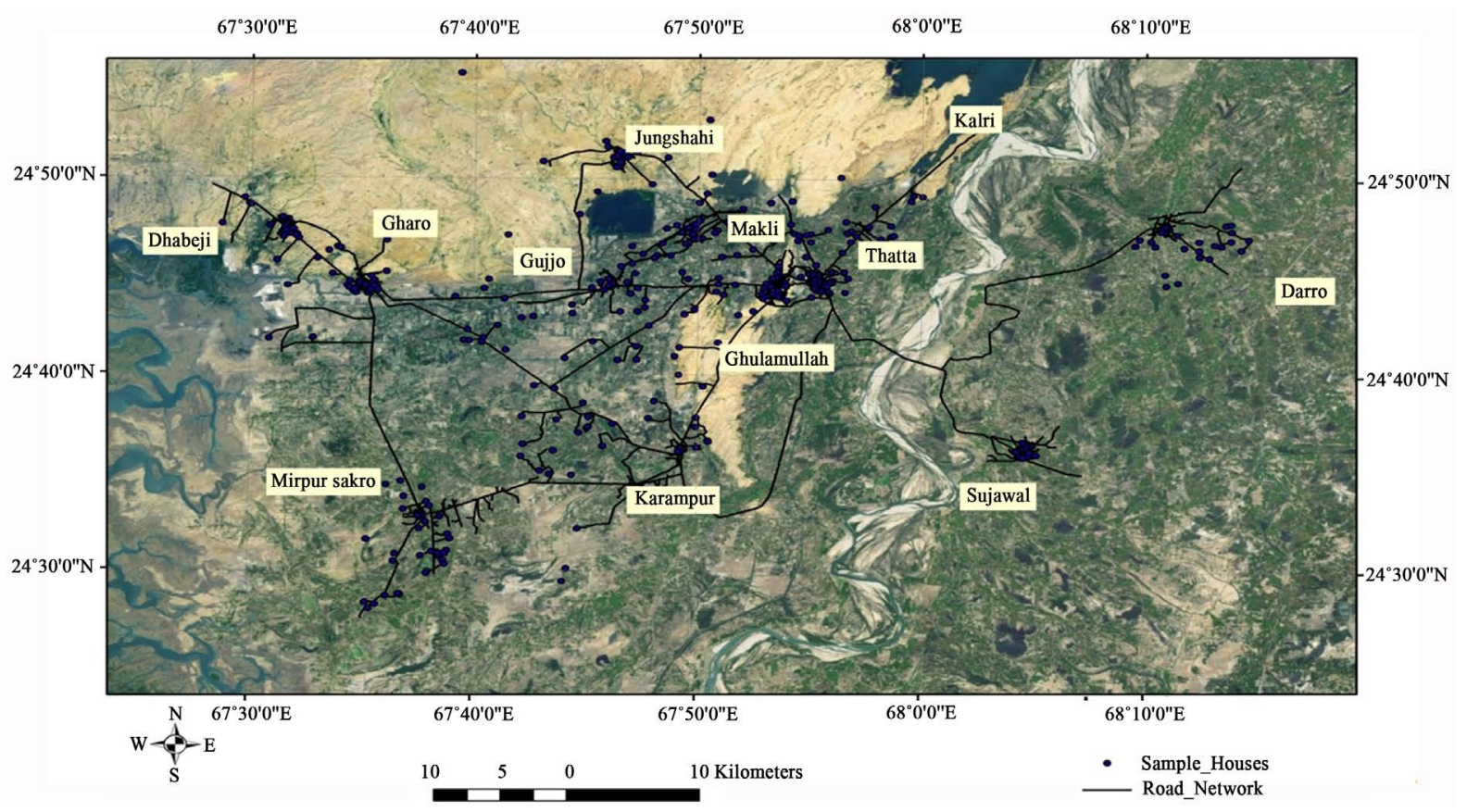

Figure 4. Spatial distribution of sampled-households in 14 sub divisions of Thatta Sindh. 
After creating the digitalized road network, the data from the GPS survey was imported into Arc GIS version 9.3 to output measures of the distances from patient homes to FP centers. Distance was calculated from household to nearest center, assuming that the women are likely to visit the center most proximate to their home. Moreover, the shortest path with respect to distance conforms to the principal of "nearest neighbor from origin" concept, which depends upon real-world route availability, as shown in Figure 5. The nearest neighbor analysis works on the principal by calculating the distance between each point and the nearest point to it [20]. For example, the coordinates of multiple FP centers were obtained in this study, but the distance was calculated from the household or village of the woman to FP center nearest to her house.

\subsection{Statistical Analysis}

Data was analyzed using IBM SPSS version 19 and STATA version 11. Chi-square and independent t-tests were applied for comparative analysis between cases and controls for categorical and continuous variables, respectively. Logistic regression was done to assess the univariate associations with risk factors, which were characterized by odds ratios (OR) and associated 95\% confidence intervals (95\% CI).

Multi-collinearity was assessed and checks were made for biological plausible interactions between independent variables. Variables having biological and significant associations ( $p$-value $<0.25$ ) with the outcome (unintended pregnancy) were assessed further in multivariate regression analysis. Variables were included in the final model by assessing their significance at a $p$-value of $<0.05$ and likelihood ratio testing. The scale of the continuous variables such as age, road network distance, and number of living sons, were checked for assumption of linearity by quartile analysis. The fit of the final model was tested using the Hosmer-Leme show test. Adjusted odds ratios with their 95\% confidence intervals were used for interpreting the results.

This study was reviewed and approved by the Ethical Review Committee of the Aga Khan University Karachi, Pakistan.

\section{Results}

Women with unintended pregnancies had a higher mean age of 29.7 years compared to women with intended pregnancies 25.5 years $(p<0.05)$. More women with unintended pregnancies, and their husbands, had an education level of "completed primary or less" (90\% and 66.5\%, respectively) as compared to women with an intended pregnancy $(82.3 \%$ and $60 \%)$. Of note, women with unintended pregnancies got married at somewhat

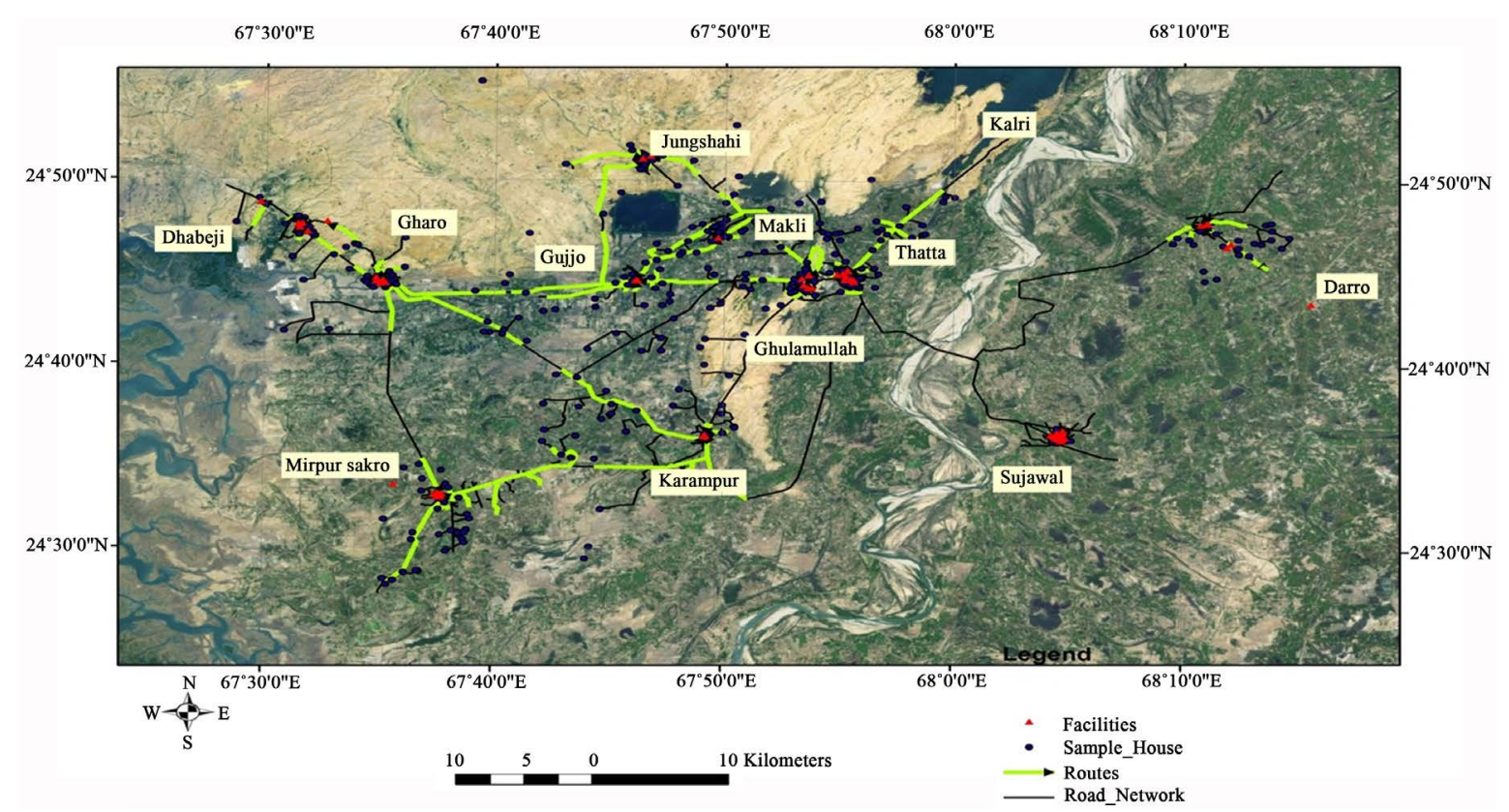

Figure 5. Distance measurement from house hold to nearest working family planning center in 14 union councils of district Thatta Sindh. 
earlier ages (19.5 years \pm 3.4 years) as compared to women who had intended pregnancies (20.1 years \pm 3.3 years), and the difference was statistically significant $(p<0.05)$. In addition, women with unintended pregnancies had a higher gravidity, number of living children, and number of sons than women with intended pregnancies (Table 1).

There was no difference in the calculated distance to FP centers from the homes of the women who reported unintended versus those who reported intended pregnancy. The median road network distance between households and the nearest FP center for women with unintended pregnancies was $0.814 \mathrm{~km}$ (IQR: 0.32, 4.6) and $0.810 \mathrm{~km}$ (IQR: $0.33,4.41$ ) for women with an intended pregnancy. In terms of transportation, $34.5 \%$ of the women with unintended pregnancies and $35.8 \%$ of the controls reported that they had access to their own transport (Table 1).

A significantly higher proportion of the women with unintended pregnancies had knowledge (62\%) about the FP centers and visited these centers (18\%) as compared to women in the control group (45.3\% and $11.5 \%$ respectively). Almost equal numbers of women in both groups mentioned that FP centers are close to their homes (women with unintended pregnancy $55.6 \%$ vs. 55.1\% women with intended pregnancy), and can be accessed on foot (66.7\% of the women with unintended pregnancy and $58.0 \%$ of the women with intended pregnancy). The majority of the women in both groups were aware of the LHW program and the availability of door to door contraceptive service provision, with $74.5 \%$ of the women with unintended pregnancies and $68.3 \%$ of the controls having been visited by a LHW at least once during their married life (mean of 10 years) (Table 1).

In terms of contraceptive knowledge and practices, $28 \%$ of the women with unintended pregnancies and $14.7 \%$ of the women with intended pregnancies had knowledge of FP methods and were using contraception before conceiving their index pregnancy. Opposition by the woman's husband and opposition to contraceptive use by the woman herself were both higher among women with unintended pregnancies than in the control group. Fear of the side effects of contraceptive use was also higher among women with unintended pregnancies, $27.5 \%$ than in women with intended pregnancy, $6.8 \%$.

Univariate analysis showed that geographic access (distance and personal transportation) was not significantly associated with unintended pregnancy (OR 0.99; 95\% CI (0.96 - 1.03) and OR: 1.06; 95\% CI (0.76 - 1.48)). Increasing age of the women [OR 1.18 (95\% CI: 1.14 - 1.22)], their primary education status [OR 2.09 (95\% CI: 0.97 - 4.52)], and the education level of their husbands [OR 1.78 (95\% CI: 1.09 - 2.91)], were found to be significantly associated with unintended pregnancy on univariate analysis. Biological factors such as increasing gravidity [OR 1.43 (95\% CI: 1.34 - 1.52)], number of living children [OR 1.72 (95\% CI: 1.58 - 1.89)], having at least one living son OR 2.15 (95\% CI: 1.78 - 2.48), and age at the time of marriage [OR 0.95 (95\% CI: 0.90 0.99)] were also associated with unintended pregnancy.

Having contraceptive knowledge and utilizing FP methods both were associated with an increased odds ratio of unintended pregnancy [5.26 (95\% CI: 2.94 - 9.41)], but interestingly, so was having contraceptive knowledge for women who were not using a contraceptive method [OR 2.91 (95\% CI: 1.17 - 4.88)]. Moreover, having a husband who opposed the use of FP methods [OR 2.89 (95\% CI: 1.45 - 5.75)], or being afraid of side effects of contraceptive use OR 5.17 [(95\% CI: 3.32 - 8.06)], also increased the risk of a woman experiencing an unintended pregnancy. On the other hand, home visits by a LHW [OR 1.35 (95\% CI: 0.94 - 1.94)] did not significantly increase the odds of unintended pregnancy.

In the final multivariate model, distance to a FP center [OR 1.00; 95\% CI (0.95 - 1.05)] and availability of personal transportation OR: 1.14; 95\% CI (0.78 - 1.67) remained insignificant predictors of unintended pregnancy (Table 2). Older age of the woman remained a positive predictor of unintended pregnancy and for each year increase in the age of the woman, the odds that her most current pregnancy was unintended increased by 1.13 [OR: 1.13; 95\% CI (1.08 - 1.17)]. Risk of unintended pregnancies also increased with increasing number of living sons. Those women who had at least one living son were three times more likely to report that their most recent pregnancy was unintended than women who had no living sons [OR: 3.13; 95\% CI (1.93 - 5.07)] (Table 2). Knowledge of FP methods with or without use was also associated with increased risk of unintended pregnancies [OR: 3.59; 95\% CI (1.83 - 7.06)] and [OR 2.21; 95\% CI (1.23 - 3.97)], respectively. Other factors associated with unintended pregnancies were having a husband whose educational level was less than or equal to primary school, [OR 1.85; 95\% CI (1.08 - 3.18)] and having a husband who is opposed to the use of FP methods [OR: 3.24; 95\% CI (1.89 - 5.56)] (Table 2)]. 
Table 1. Univariate logistic regression for association of geographic access and other covariates with unintended pregnancy among women of district Thatta, Sindh Pakistan.

\begin{tabular}{|c|c|c|c|}
\hline Characteristic & Cases & Controls & Unadjusted ORs \\
\hline \multicolumn{4}{|l|}{ Socio-demographics } \\
\hline Age & $29.66 \pm 4.80^{*}$ & $25.50 \pm 4.89^{*}$ & $1.18[1.14-1.22]^{* * *}$ \\
\hline $\begin{array}{l}\text { Women's education } \\
\text { Intermediate and above } \\
\text { Middle to secondary } \\
\text { Primary or less }\end{array}$ & $\begin{array}{c}180[90 \%] \\
12[6 \%] \\
8[4 \%]\end{array}$ & $\begin{array}{c}494[82.3 \%] \\
60[10 \%] \\
46[7.7 \%]\end{array}$ & $\begin{array}{c}1 \\
1.15[0.42-3.04] \\
2.09[0.97-4.52]^{* * *}\end{array}$ \\
\hline $\begin{array}{l}\text { Husband's Education } \\
\text { Intermediate and above } \\
\text { Middle to secondary } \\
\text { Primary or less }\end{array}$ & $\begin{array}{c}133[66.5 \%] \\
44[22 \%] \\
23[11.5 \%]\end{array}$ & $\begin{array}{c}360[60 \%] \\
129[21.5 \%] \\
111[18.5 \%]\end{array}$ & $\begin{array}{c}1 \\
1.65[0.94-2.90] \\
1.78[1.09-2.91]^{* *}\end{array}$ \\
\hline $\begin{array}{l}\text { Women autonomy } \\
\text { Yes } \\
\text { No }\end{array}$ & $\begin{array}{c}163[81.5 \%] \\
37[18.5 \%]\end{array}$ & $\begin{array}{l}438[73 \%] \\
162[27 \%]\end{array}$ & $\begin{array}{c}1 \\
0.61[0.41-0.91]^{* * *}\end{array}$ \\
\hline Socio-economic score & $11.5[9,14]^{\dagger}$ & $12[9.25,16]^{\dagger}$ & $0.97[0.94-1.00]^{* *}$ \\
\hline $\begin{array}{l}\text { Religion } \\
\text { Non-Muslim } \\
\text { Muslim }\end{array}$ & $\begin{array}{c}6[3 \%] \\
194[97 \%]\end{array}$ & $\begin{array}{c}21[3.5 \%] \\
579[96.5 \%]\end{array}$ & $\frac{1}{1.17[0.47-2.95]}$ \\
\hline \multicolumn{4}{|l|}{ Fertility and access to FP services } \\
\hline Age at marriage & $19.48 \pm 3.44^{*}$ & $20.06 \pm 3.33^{*}$ & $0.95[0.90-0.99]^{* * *}$ \\
\hline Gravidity & $5[4,8]^{\dagger}$ & $2[1,4]^{\dagger}$ & $1.43[1.34-1.52]^{* * *}$ \\
\hline Number of alive children & $4[3,6]^{\dagger}$ & $1[0,3]^{\dagger}$ & $1.72[1.58-1.89]^{* * *}$ \\
\hline $\begin{array}{l}\text { Number of alive sons } \\
\text { No alive son } \\
\text { At least one alive son }\end{array}$ & $\begin{array}{c}26[13 \%] \\
174[87 \%]\end{array}$ & $\begin{array}{l}300[50 \%] \\
300[50 \%]\end{array}$ & $2.15[1.87-2.48]^{* * *}$ \\
\hline Distance of FP center from house of women & $0.81[0.32,4.61]^{\dagger}$ & $0.81[0.33,4.41]^{\dagger}$ & $0.99[0.96-1.03]$ \\
\hline $\begin{array}{l}\text { Availability of personal transport } \\
\text { Yes } \\
\text { No }\end{array}$ & $\begin{array}{c}69[34.5 \%] \\
131[65.5 \%]\end{array}$ & $\begin{array}{l}215[35.8 \%] \\
385[64.2 \%]\end{array}$ & $1.06[0.76-1.48]$ \\
\hline $\begin{array}{l}\text { Awareness of FP centre } \\
\text { Yes } \\
\text { No }\end{array}$ & $\begin{array}{c}124[62 \%] \\
76[38 \%]\end{array}$ & $\begin{array}{l}272[45.3 \%] \\
528[54.7 \%]\end{array}$ & $0.51[0.37-0.71]^{* * *}$ \\
\hline $\begin{array}{l}\text { Visited FP centre for availing services } \\
\text { Yes } \\
\text { No }\end{array}$ & $\begin{array}{c}36[18 \%] \\
164[82 \%]\end{array}$ & $\begin{array}{c}69[11.5 \%] \\
531[88.5 \%]\end{array}$ & $0.59[0.38-0.92]^{* * *}$ \\
\hline \multicolumn{4}{|c|}{ Knowledge and family planning service provision by LHWs } \\
\hline $\begin{array}{l}\text { Awareness about LHWs } \\
\text { Yes } \\
\text { No }\end{array}$ & $\begin{array}{l}162[81 \%] \\
38[19 \%]\end{array}$ & $\begin{array}{l}476[79.3 \%] \\
124[21.7 \%]\end{array}$ & $0.9[0.60-1.35]$ \\
\hline $\begin{array}{l}\text { Door step visit by LHWs at least once } \\
\text { No } \\
\text { Yes }\end{array}$ & $\begin{array}{c}51[25.5 \%] \\
149[74.5 \%]\end{array}$ & $\begin{array}{l}190[31.7 \%] \\
410[68.3 \%]\end{array}$ & $1.35[0.94-1.94]^{* *}$ \\
\hline $\begin{array}{l}\text { Ever discussion about FP with woman by LH } \\
\text { Yes } \\
\text { No }\end{array}$ & $\begin{array}{c}61[30.5 \%] \\
139[69.5 \%]\end{array}$ & $\begin{array}{l}100[16.7 \%] \\
500[83.3 \%]\end{array}$ & $0.46[0.31-0.66]^{* * *}$ \\
\hline $\begin{array}{l}\text { FP method offered by LHW } \\
\text { Yes } \\
\text { No }\end{array}$ & $\begin{array}{c}31[15.5 \%] \\
169[84.5 \%]\end{array}$ & $\begin{array}{c}46[7.7 \%] \\
554[92.3 \%]\end{array}$ & $\begin{array}{c}1 \\
0.45[0.28-0.74]^{* * *}\end{array}$ \\
\hline
\end{tabular}




\section{Continued}

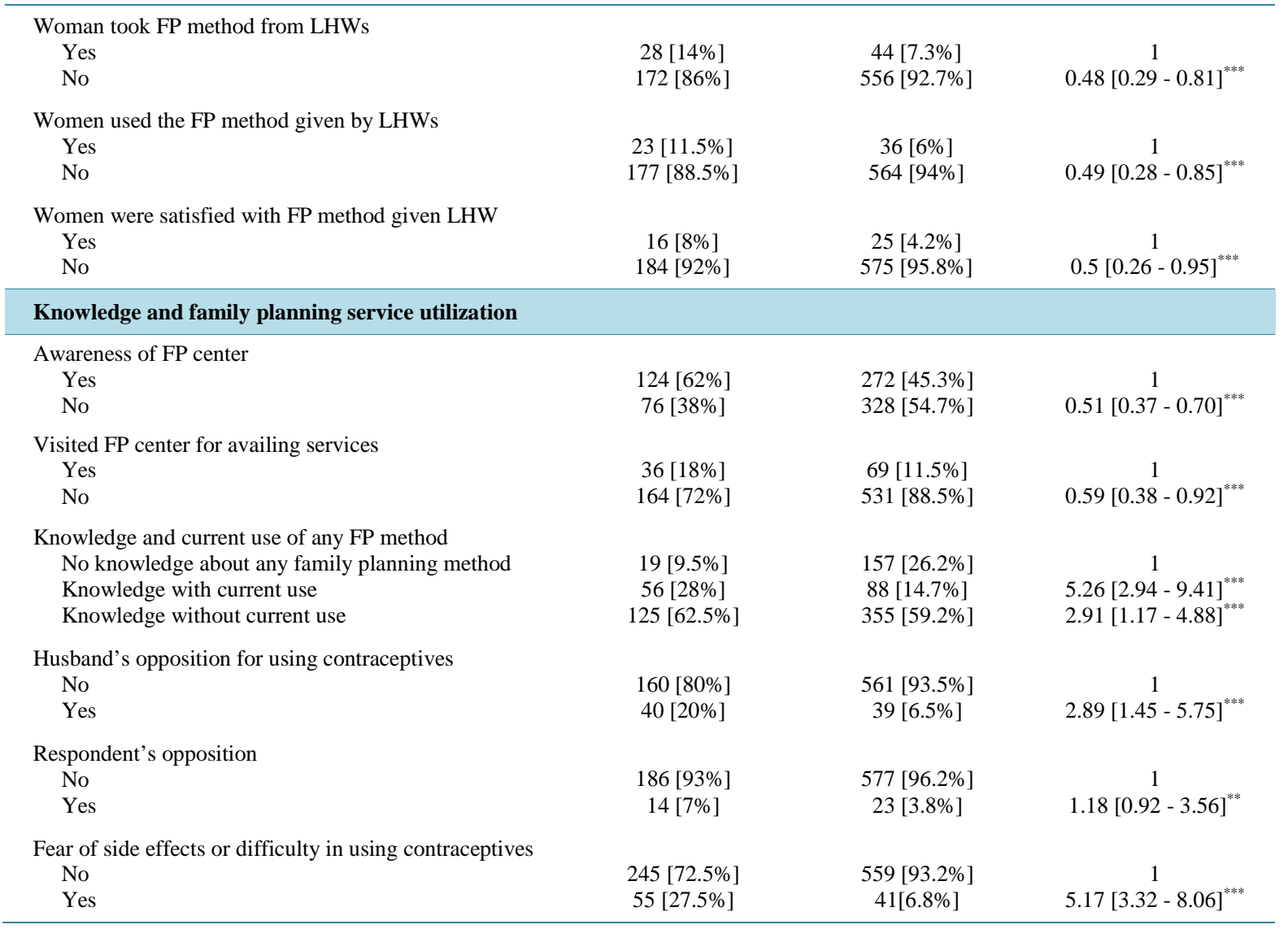

${ }^{*}$ Mean \pm SD [all such values]. ${ }^{\dagger}$ Median, interquartile range in parenthesis [all such values]. ${ }^{* *} p$-value $<0.25 ;{ }^{* * *} p$-value $<0.05$. OR: Odd ratio, CI: Confidence interval.

Table 2. Multivariate logistic regression model predicting risk of unintended pregnancy.

\begin{tabular}{|c|c|}
\hline Variable & Adjusted OR [95\% CI] \\
\hline Distance $[\mathrm{km}]$ & $1,[0.95-1.05]$ \\
\hline $\begin{array}{l}\text { Having personal transportation } \\
\text { Not having personal transportation }\end{array}$ & $\begin{array}{c}1 \\
1.14,[0.78-1.67]\end{array}$ \\
\hline Maternal age & 1.13, [1.08 - 1.17] \\
\hline $\begin{array}{l}\text { Alive sons } \\
\text { No alive son } \\
\text { At least one alive son }\end{array}$ & $\begin{array}{c}1 \\
3.13,[1.93-5.07]\end{array}$ \\
\hline $\begin{array}{l}\text { Educational status of husband } \\
\text { Intermediate and above } \\
\text { Middle to secondary } \\
\text { Primary or less }\end{array}$ & $\begin{array}{c}1 \\
1.68,[0.90-3.14] \\
1.85,[1.08-3.18]\end{array}$ \\
\hline $\begin{array}{l}\text { Knowledge and current use of any } \mathrm{F} \\
\text { No knowledge } \\
\text { Knowledge with current use } \\
\text { Knowledge without current use }\end{array}$ & $\begin{array}{c}1 \\
3.59,[1.83-7.06] \\
2.21,[1.23-3.97]\end{array}$ \\
\hline $\begin{array}{l}\text { Husband's opposition } \\
\text { No husband's opposition } \\
\text { Husband's opposition }\end{array}$ & $\begin{array}{c}1 \\
3.24,[1.89-5.56]\end{array}$ \\
\hline
\end{tabular}

OR: Odd ratio, CI: Confidence interval. 


\section{Discussion}

\subsection{Main Findings}

This study indicates that geographic access has no measurable impact on the occurrence of unintended pregnancies in the catchment population of Thatta district. This relationship between distance and unintended pregnancy was assessed after categorizing the distance into $>2,>5$ and $>10$ kilometers but the association remained insignificant. This might be due to the fact that, healthcare centres providing FP services are not very far from the homes of women as evidenced by geographical data (Figure 2). More than half of the women (56\%) sampled lived within 1 kilometer of a FP center and majority is able to walk to these facilities. This finding differs from prior studies in Pakistan, which determined that only $10 \%$ of the population was living within walking distance of a government operated FP centers [15].

Comparison of distance as an indicator of access to FP services with other studies is difficult, as most of the available literature has assessed the impact of geographic access on the use of health services in general. Studies looking at the impact of geographic access on use of FP services vary from country to country. Our findings are consistent with evidence from Nepal and Thailand that demonstrates that distance is not a limiting factor for access to FP services [21] [22]. However, a multi-country study suggests that some relationship does exist between distance to facilities and use of contraceptives, but it was at the univariable level [13].

This study showed that women with unintended pregnancies were more likely to be older. Targeting this population subgroup with specific programs might reduce unintended pregnancy in this region of Pakistan. These findings were consistent with the study conducted in Nepal [21]. Additionally, women with at least one son were more likely to experience unintended pregnancies. Male child preference is common in Asian countries [23]. Women who have a living male child may be interested in preventing pregnancy for the sake of a longer interpregnancy interval, or may no longer desire fertility, but experience unintended pregnancy due to limited contraceptive use or access. These findings are consistent with previous research [23] and PDHS 2012-2013 data shows that $60 \%$ of the women with three sons do not want to be pregnant any more [6].

Another important finding is that almost twice as many women who had unintended pregnancies knew about and were using a modern FP methods before their index pregnancy (28\%) as compared to women with intended pregnancies (14\%). Women using a FP method were more likely to regard a pregnancy occurring as unintended, consistent with previous international research [24]. In settings with low CPR (21.6\%), non-use of modern FP methods would be expected to account for unintended pregnancies; but in our sample, almost one-third of women experienced unintended pregnancy due to method failure. Methods most frequently used in this sample were injectable contraceptives (47.9\%), condoms (28.5\%), and hormonal contraceptive pills (27.1\%). Longactive reversible contraceptive (LARC) methods (hormonal implants (1.4\%) and IUCD (3.5\%)) were rarely used. We did not explore the reasons of method failure, but prior research suggests that common reasons include missed pills or doses of injectable contraceptives, condom breakage, and supply chain issues [25]. Other reasons suggested by our analysis include lack of spousal support, fear of side effects, or difficulty in using available methods, with $27.5 \%$ of the women with unintended pregnancies, referencing one of the last two reasons for not using any method.

Women whose husbands were opposed to contraceptive use or were less educated were more likely to face unintended pregnancy. Both members in a couple should be equally responsible for FP, but to date the responsibility of Pakistani men has largely been neglected. As a topic for further research, collecting information about men's attitudes toward and knowledge about use of contraceptives could contribute greatly to an understanding of FP generally, and unintended pregnancy specifically. The quality of a couple's relationship and their interspousal communication has been shown to have an effect on contraceptive use [26]. Thus, couples counseling and targeted counseling of men during the peripartum period should be included in any targeted interventions to increase FP utilization and reduce unintended pregnancies. In addition to contraceptive counseling, educational levels of men also appear to be integral to the issue of unintended pregnancy in this population. The literacy rate of men in Thatta district is very low and more than half of the men had only primary education or less. While this represents a systemic problem that would not be addressed by any specific FP intervention and would require a commitment to strengthening education on a greater level in the country, it is important to note that women married to uneducated men are at increased risk of unintended pregnancy and require even more attention for effective FP counseling and education about contraceptive methods. 


\subsection{Strengths and Limitations}

An important strength of the study was the enrollment of pregnant women in the first trimester which presumably allowed for more accurate assessment of pregnancy intention, which reduced recall bias. Secondly, a validated questionnaire based on the standard demographic definition of unintended pregnancy, was used [17]. Third, cases and controls were selected from the same cohort of MNH registry to overcome selection bias. Data collectors were blinded about the status of pregnancy intention to ensure comparability of information between groups. Distance was measured objectively to overcome recall bias. Finally, road network distance was calculated with the help of GIS, which gives better representation of access and provides more accurate estimates than other methods which ignore topography [27]. In terms of limitations, it is possible that, women might not have correctly responded about the knowledge and use of contraceptives due to the sensitive nature of these questions, culturally. However, every effort was made to interview women privately, but it may not have made them comfortable enough to discuss topics that are generally considered private. Distance was calculated from household to nearest FP center irrespective of whether the woman was actually utilizing services from that center, or not. Finally, the fertility preferences were elicited only from women without considering preferences of husbands.

\section{Conclusions}

Lack of geographic access to working FP centers was not found to be associated with unintended pregnancies in Thatta district. However, based on our analysis, we proposed that the subgroup of older women with at least one living son should be targeted for FP services. This program might be focused on immediate postpartum contraception which has been shown to be a very effective time for intervention [28]. Moreover, antenatal care visits provide an opportunity to identify and counsel this specific group on contraception generally, and for early postpartum contraceptive placement, specifically [28]. The antepartum, intrapartum, and post-partum periods are crucial time points for behavior change and targeted interventions can motivate a couple to adapt a FP method when they are appropriately counseled [29].

We also propose that the quality of FP programs should be improved with active promotion of LARC methods and use of emergency contraception. Previous analyses suggest that sufficient information about emergency contraception is generally not conveyed effectively [29]. Finally, we believe that more attention needs to be paid to the role of husbands in FP with special attention to uneducated men. The aforementioned factors could result in reduction of the unintended pregnancies, which will improve welfare of the family in a country chronically plagued by poor maternal, fetal, and neonatal pregnancy outcomes [31].

Further studies need to be conducted with special attention to the role of men, to the causes of method failure and non-use of contraceptive methods, with attention to how they impact both intended and unintended pregnancy rates.

\section{Acknowledgements}

I would in particular like to mention Mr. Iqbal Azam for his guidance and support whenever required. His knowledge and wisdom helped me to better understand the difficult concepts related to his expertise.

\section{Competing Interest}

Author declares that there is no financial or non-financial competing interest for this work.

\section{Funding}

This study was carried out as a thesis work for MSc Epidemiology and Biostatistics offered by the Aga Khan University. As part of the program and as per university policy I was given 100,000 PKR (approximately USD 1000 ) for carrying out my research work.

\section{Details of Ethics Approval}

This study was reviewed and approved by the Ethical Review Committee of the Aga Khan University Karachi, Pakistan. 


\section{Authors' Contributions}

Contribution by Dr. Sumera Aziz Ali: Dr. Sumera Aziz Ali had made the proposal, developed the questionnaire, manual of operations, data collection, cleaning of data and did the analysis for this paper. She has substantial contributions to conception and design and acquisition of data or analysis and interpretation of data. She drafted the manuscript which was finalized by contribution from other authors. She also gave the final approval of the version to be published. She is also accountable for all aspects of the work in ensuring that questions related to the accuracy or integrity of any part of the work are appropriately investigated and resolved.

Contribution by Dr. Sarah Saleem: Dr. Sarah Saleem gave her feedback during hypothesis formulation and development of research question. She also gave her rigorous feedback for analysis and reviewed the manuscript critically. She had been involved in drafting complete manuscript and revising it critically for all aspects and has given final approval of the version to be published.

Contribution by Dr. Neelofar Sami: Dr. Neelofar Sami gave her feedback during hypothesis formulation, development of research question and questionnaire. She also helped in formation of manual of operation to conduct the study. She gave her feedback for introduction part of the manuscript.

Contribution by Prof. Dr. Mir Shabbar Ali: Prof. Dr. Mir Shabbar Ali advised in planning and execution of GPS survey and development of GIS maps with special reference to transportation infrastructure of the study area.

Contribution by Mohammad Ahmed: Mr. Mohammad Ahmed helped in technical part of GIS; he supervised in marking the GPS coordinates and road mapping for different sub divisions. He also did the analysis on Arc GIS and generated the variable for distance on GIS.

Contribution by Dr. Shafquat Rozi: Dr. ShafquatRozi helped in the analysis for the complete data and gave her regular feedback at every step of analysis.

Contribution by Dr. Robert L. Goldenberg (MD, Professor): Dr. Goldenberg provided his valuable feedback for each heading of the manuscript including introduction, methods, results, discussion and conclusion by reviewing the manuscript critically. He has given final approval of the version to be published.

Contribution by Dr. Margo S. Harrison (MD, MPH): Dr. Harrison gave provided his valuable feedback for each heading of the manuscript including introduction, methods, results, discussion and conclusion by reviewing the manuscript critically. He has given final approval of the version to be published.

Contribution by Dr. Omrana Pasha: Dr. Omrana was main supervisor for this study and she supervised at every step including proposal writing, data collection, data analysis and interpretation of data. She also helped in drafting the manuscript.

\section{References}

[1] Yazdkhasti, M., et al. (2015) Unintended Pregnancy and Its Adverse Social and Economic Consequences on Health System: A Narrative Review Article. Iranian Journal of Public Health, 44, 12-21.

[2] Shah, P.S., et al. (2011) Intention to Become Pregnant and Low Birth Weight and Preterm Birth: A Systematic Review. Maternal and Child Health Journal, 15, 205-216. http://dx.doi.org/10.1007/s10995-009-0546-2

[3] Smith, R., Population Reference Bureau (2009) Family Planning Saves Lives. Population Reference Bureau, Washington DC.

[4] Sathar, Z., et al. (2014) Induced Abortions and Unintended Pregnancies in Pakistan. Studies in Family Planning, 45, 471-491. http://dx.doi.org/10.1111/j.1728-4465.2014.00004.x

[5] Gazdar, H., Khan, A. and Qureshi, S. (2012) Causes and Implications of Induced Abortion in Pakistan, a Social and Economic Analysis. Research Report. Collective for Social Science Research, Karachi.

[6] Calverton, M.U., Macro International Inc. (2012-2013) Demographic and Health Survey. National Institute of Population Studies, Islamabad.

[7] Kost, K., et al. (2008) Estimates of Contraceptive Failure from the 2002 National Survey of Family Growth. Contraception, 77, 10-21. http://dx.doi.org/10.1016/j.contraception.2007.09.013

[8] Bhattathiry, M.M. and Ethirajan, N. (2014) Unmet Need for Family Planning among Married Women of Reproductive Age Group in Urban Tamil Nadu. Journal of Family \& Community Medicine, 21, 53. http://dx.doi.org/10.4103/2230-8229.128786

[9] Tsui, A.O., McDonald-Mosley, R. and Burke, A.E. (2010) Family Planning and the Burden of Unintended Pregnancies. Epidemiologic Reviews, 32, 152-174. http://dx.doi.org/10.1093/epirev/mxq012

[10] Hardee, K. (2005) The Intersection of Gender, Access, and Quality of Care in Reproductive Services: Examples from 
Kenya, India, and Guatemala. USAID.

[11] Yamashita, T. and Kunkel, S.R. (2010) The Association between Heart Disease Mortality and Geographic Access to Hospitals: County Level Comparisons in Ohio, USA. Social Science \& Medicine, 70, 1211-1218. http://dx.doi.org/10.1016/j.socscimed.2009.12.028

[12] Arcury, T.A., Preisser, J.S., Gesler, W.M. and Powers, J.M. (2005) Access to Transportation and Health Care Utilization in a Rural Region. The Journal of Rural Health, 21, 31-38. http://dx.doi.org/10.1111/j.1748-0361.2005.tb00059.x

[13] Bongaarts, J. and Bruce, J. (1995) The Causes of Unmet Need for Contraception and the Social Content of Services. Studies in Family Planning, 26, 57-75. http://dx.doi.org/10.2307/2137932

[14] Ahmed, B. (1987) Determinants of Contraceptive Use in Rural Bangladesh: The Demand for Children, Supply of Children, and Costs of Fertility Regulation. Demography, 24, 361-373. http://dx.doi.org/10.2307/2061303

[15] Stephenson, R. and Hennink, M. (2004) Barriers to Family Planning Use amongst the Urban Poor in Pakistan.

[16] Goudar, S.S., Carlo, W.A., McClure, E.M., Pasha, O., Patel, A., Esamai, F., et al. (2012) The Maternal and Newborn Health Registry Study of the Global Network for Women's and Children's Health Research. International Journal of Gynecology \& Obstetrics, 118, 190-193.

[17] Inc., M.I. and Calverton, M.U. (2008) Demographic and Health Survey. National Institute of Population Studies Islamabad, Pakistan. Chap. 5, 6 \& 7, 53-88.

[18] Hafeez, A., Mohamud, B.K., Shiekh, M.R., Shah, S.A. and Jooma, R. (2011) Lady Health Workers Programme in Pakistan: Challenges, Achievements and the Way Forward. Journal of the Pakistan Medical Association, 61, $210-215$.

[19] Mahmood, N. and Ringheim, K. (1997) Knowledge, Approval and Communication about Family Planning as Correlates of Desired Fertility among Spouses in Pakistan. International Family Planning Perspectives, 23, 122-145. http://dx.doi.org/10.2307/2950768

[20] Gao, M. (2013) Detecting Spatial Aggregation from Distance Sampling: A Probability Distribution Model of Nearest Neighbor Distance. Ecological Research, 28, 397-405. http://dx.doi.org/10.1007/s11284-013-1029-x

[21] Adhikari, R., Soonthorndhada, K. and Prasartkul, P. (2009) Correlates of Unintended Pregnancy among Currently Pregnant Married Women in Nepal. BMC International Health and Human Rights, 9, 17. http://dx.doi.org/10.1186/1472-698X-9-17

[22] Chamratrithirong, A., Kamnuansilpa, P. and Knodel, J. (1986) Contraceptive Practice and Fertility in Thailand: Results of the Third Contraceptive Prevalence Survey. Studies in Family Planning, 17, 278-287. http://dx.doi.org/10.2307/1966905

[23] Cu Le, L., Magnani, R., Rice, J., Speizer, I. and Bertrand, W. (2004) Reassessing the Level of Unintended Pregnancy and Its Correlates in Vietnam. Studies in Family Planning, 35, 15-26. http://dx.doi.org/10.1111/j.1728-4465.2004.00002.x

[24] Islam, M.M. and Rashid, M. (2005) Determinants of Unintended Pregnancy among Ever-Married Women in Bangladesh. Journal of Family Welfare, 50, 40-47.

[25] Keshtkaran, A. (2005) The Survey of Effective Factors on Different Practical Failure Methods of Family Planning in Women Referred to Health Centers. Middle East Journal of Family Medicine, 3.

[26] Islam, M.S., Alam, M.S. and Hasan, M.M. (2014) Inter-Spousal Communication on Family Planning and Its Effect on Contraceptive Use and Method Choice in Bangladesh. Asian Social Science, 10, 189-196.

[27] Gibson, J., Deng, X.Z., Boe-Gibson, G., Rozelle, S. and Huang, J.K. (2011) Which Households Are Most Distant from Health Centers in Rural China? Evidence from a GIS Network Analysis. GeoJournal, 76, 245-255. http://dx.doi.org/10.1007/s10708-010-9337-y

[28] Zapata, L.B., Murtaza, S., Whiteman, M.K., Jamieson, D.J., Robbins, C.L., Marchbanks, P.A., D’Angelo, D.V. and Curtis, K.M. (2015) Contraceptive Counseling and Postpartum Contraceptive Use. American Journal of Obstetrics and Gynecology, 212, 171.e1-171.e8. http://dx.doi.org/10.1016/j.ajog.2014.07.059

[29] Lauria, L., Donati, S., Spinelli, A., Bonciani, M. and Grandolfo, M.E. (2014) The Effect of Contraceptive Counselling in the Pre- and Post-Natal Period on Contraceptive Use at Three Months after Delivery among Italian and Immigrant Women. Annali dell'Istituto Superiore di Sanitã, 50, 54-61.

[30] Saleem, S., et al. (2002) Emergency Contraception. Journal of the College of Physicians and Surgeons Pakistan, 12, 232-235.

[31] Pasha, O., Goudar, S.S., Patel, A., Garces, A., Esamai, F., Chomba, E., et al. (2015) Postpartum Contraceptive Use and Unmet Need for Family Planning in Five Low-Income Countries. Reproductive Health, 12, S11. http://dx.doi.org/10.1186/1742-4755-12-s2-s11 


\section{List of Abbreviations}

PDHS

$\mathrm{MNH}$

CPR

GIS

LHWs

NGOs

FP

ID\#

GPS

OR

CI

ERC

$\mathrm{Km}$

UC
Pakistan Demographic and Health Survey

Maternal-New born Health

Contraceptive Prevalence Rate

Geographic Information System

Lady Health Workers

Non-Governmental Organizations

Family Planning

Identification Number

Global Positioning System

Odds Ratio

Confidence Interval

Ethical Review Committee

Kilometer

Union Council 